Original

\title{
Design of a unique PCR primer for detection of oral HPV infection
}

\author{
Toshikazu Kuroki, Osamu Tsuzukibashi*, Masayuki Saito*, Shinichi Kuribayashi*, \\ Yasuhiro Shimpuku* and Masaharu Makimura* \\ Departments of Comprehensive Dentistry and *Clinical Pathology, \\ Nihon University School of Dentistry at Matsudo, Chiba 271-8587
}

(Received 3 March and accepted 11 November 2000)

\begin{abstract}
Human papillomavirus (HPV) has been known as a pathogen of oral dysplasia. However, suitable PCR primers for the detection of oral HPV infection have not been reported. The aim of this study was to design unique consensus primers. The consensus primers were designed by homologues analyses between subtypes $2,6,11,13,16,18,30,32$ and 58 , which frequently infect the oral membrane. PCR, with our designed primer, detected HPV DNA subtypes 2, 6, 11, 16, 18 and 58, and also showed PCR product from a clinical papilloma sample. These results indicate that our designed consensus primer can be used for the study of the relationships between oral disease and HPV infection. (J. Oral Sci. 42, 189-193, 2000)
\end{abstract}

Key words: human papillomavirus; PCR; consensus primer.

\section{Introduction}

Human papillomavirus (HPV) infection is thought to be responsible for not only the production of papilloma but also occultation of malignant. HPV has been classified into over 60 different types based on DNA hybridization criteria (1). In the case of dysplasia, subtyping of detected HPVDNA is important for the determination of the prognosis for cervical disease. Subtypes 16, 18, 31, 33, 35, 45, 51, 52,56 and 58 are known as malignant generative subtypes

Correspondence to Dr. Toshikazu Kuroki, Department of Comprehensive Dentistry, Nihon University School of Dentistry at Matsudo, 2-870-1 Sakaecho-nishi, Matsudo, Chiba 271-8587, Japan
(1-4). On the other hand, HPV (subtype 2, 6, 11, 16, 30 and 32) also can infect the oral membrane and generate dysplasia (5).

Recently, many viral and bacterial infectious diseases have been diagnosed and analyzed using genetic methods. Polymerase chain reaction (PCR) can detect unique DNA segments of interest (6). However, the genetic methods used for detection and subtyping of HPV have been mostly performed on gynecological diseases, with not enough being performed on oral dysplasia. This phenomenon is the result of the differences of subtype group between the gynecological and oral region. In this study, we designed unique consensus PCR primers to detect HPV infection on the oral membrane.

\section{Materials and Methods \\ HPV-DNA}

Control genome YG-VG009 (HPV-2), YG-VG010 (HPV-4), YG-VG011 (HPV-6), YG-VG012 (HPV-11), YG-VG013 (HPV-16), YG-VG014 (HPV-18) and YGVG040 (HPV-58) were obtained from the Health Science Research Resources Bank. HPV-16 infected cells (CaSki) (7) were purchased from Dainippon Pharmaceutical, and used as a control sample. The five clinical specimens of oral papilloma were taken from patients in the hospital attached to the Nihon University School of Dentistry at Matsudo.

\section{DNA preparation}

DNA preparation from sample cells were performed using the method of Davis et al. (8). Extracted DNA samples were dissolved in TE buffer and stored at $-70^{\circ} \mathrm{C}$ until use. 


\section{PCR primers}

In order to arrange the consensus primers for the detection of oral HPV infection, the homology of nucleotide sequence between HPV-2, 11, 13, 16, 18, 30 and 32 were examined. The complete genome sequence data of the above HPV subtypes were referred from the GenBank ${ }^{\mathrm{TM}}$ (National Center for Biotechnology Information). The homology analysis and design of PCR primers were performed using a personal computer (Macintosh PowerPC MT300) with gene analysis software (GENETIX-MACTM, SOFTWARE DEVELOPMENT). Designed oligonucleotide primers were synthesized by Takara Shuzo. Commercialized primers (HPVp16R, HPVp18R, HPVp33R and HPVpF, Takara Shuzo) were used as controls.

\section{Amplification and detection of HPV-DNA}

One $\mu \mathrm{g}$ of extracted DNA was used for PCR. $50 \mu \mathrm{l}$ of PCR reaction mixture contained $10 \mathrm{mM}$ Tris- $\mathrm{HCl}$ (pH8.0), $50 \mathrm{mM} \mathrm{KCl}, 1.5 \mathrm{mM} \mathrm{MgCl}, 250 \mu \mathrm{M}$ of each dNTP mix (dATP, dCTP, dGTP and dTTP), 2.5 units Taq-polymerase (TaKaRa Taq ${ }^{\mathrm{TM}}$, Takara Shuzo) and 50 pmol of each consensus primer.

The cycles were performed on a DNA Thermal Cyclar (Perkin-Elmer Cetus) at 30 cycles for $1 \mathrm{~min}$ at $94^{\circ} \mathrm{C}$ for denaturation, $2 \mathrm{~min}$ at $55^{\circ} \mathrm{C}$ for annealing, and $2 \mathrm{~min}$ at $74^{\circ} \mathrm{C}$ for elongation. After amplification, the reaction mixture was electrophoresed on a $1.2 \%$ agarose gel (Takara Shuzo), and stained with ethidium bromide for visualization of amplified DNA fragments under a UV-lamp (302 nm).

\section{Dot blot hybridization}

To confirm the specificity of the PCR amplification with the designed primer, dot blot hybridization was performed with digoxigenin (DIG) - labeled PCR product. The control genome YG-VG013 (HPV-16) was amplified and labeled by DIG (DIG DNA Labeling kit, Boehringer Mannheim). Ten $\mu \mathrm{g}$ of extracted DNA from CaSki cells or clinically normal buccal mucous were blotted on nylon membranes and hybridized with denatured DIG-labeled DNA for overnight at $42^{\circ} \mathrm{C}$. The membrane was washed two times with $2 \times$ SSC and $0.1 \%$ SDS for $15 \mathrm{~min}$ at room temperature and then three times with $0.1 \mathrm{x} \mathrm{SSC}$ and 0.1 $\%$ SDS for $15 \mathrm{~min}$ at $68^{\circ} \mathrm{C}$. The positive spot was optimized by alkaline phosphatase conjugated anti-DIG and substrate solution (NBT, BCIP).

\section{Results}

Homology of the nucleotide sequences of HPV-2, 6, 11, $13,16,18,30,32$ and 58 were analyzed. The suitable primer site was found in the L1 ORF region. The designed PCR primer pairs were MHPVFW (5' ATTCAGGATGGTGATATGG 3') for sense and MHPVRE (5' CCCCAG CAAATGCCATTATTGTG 3') for anti-sense. The location of designed primers in HPV-16 and the alignment of consensus primers with corresponding sequences of the above HPV subtypes are shown in Figs.1 and 2. The expected size of PCR products were 386 bps (type 13), 392 bps (type 2), 395 bps (type 6, 11, 16, 18, 32 and 58) and 404 bps (type 33).

DIG-labeled amplified DNA was hybridized with extracted DNA from CaSki cells but not with the normal buccal mucosa (Fig. 3).

PCR amplification with designed primers showed PCR products with expected size on HPV-2, 6, 11, 16, 18 and 58 from the control genome and the DNA extraction from CaSki cells, however, no PCR products were observed on HPV-4 from the control genome (Fig. 4).

The results showed that PCR amplification of clinical samples with our designed primers, but not control primers, possessed the specific band for HPV (Fig. 5). No remarkable non-specific bands were observed.

\section{Discussion}

The designed and selected primers were located in the L1 ORF region. The other commercial primers, which are mostly used for the gynecological region, were located on E6 to E7 ORFs (HPVp16R, HPVp18R, HPVp33R, HPVpF, pU-1M, pU-31B and pU-2R, Takara Shuzo). E1 $(9,10)$ and L1 ORFs (10-12) were also used for PCR. The L1 region was deleted in some cases (13), and the E6 and E7 regions were preferentially conserved (14-17). However, PCR amplification for the papilloma sample showed a product in this experiment. This result suggests that the $\mathrm{L} 1$ region still can be of use for the detection of oral HPV infection by PCR.

Our designed primer successfully amplified target fragments from cloned HPV-DNA subtypes 2, 6, 11, 16, 18 and 58. Subtype 4 did not find a suitable annealing site with our sense primer by sequence homologous analyses. The PCR amplification of HPV-DNA with designed primers demonstrated that this primer pair could be used for the detection of oral HPV infection. The result of dot blot hybridization with amplified and DIG-labeled fragments against normal and CaSki cell's DNA demonstrated that amplified fragments had homologous sequences with the original HPV16. These consensus primers had several mismatch sequences against other subtypes, except for type 16 (Fig. 2). The chance of PCR amplification is sometimes obstructed by mismatch sequences in the primer. Therefore, the annealing temperature affects reproduction and specificity of the PCR reaction. Although specific bands 


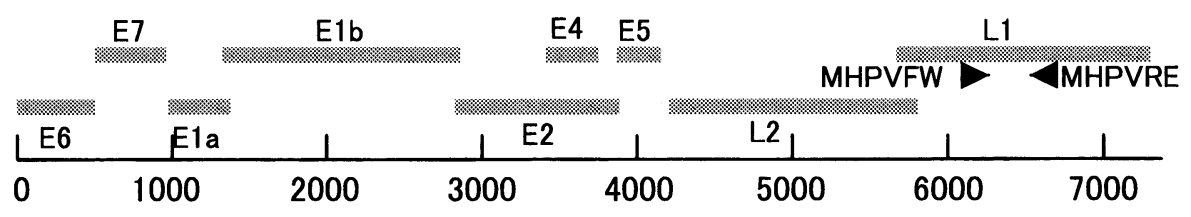

Fig. 1 Location of consensus primers (MHPVFW and MHPVRE) in the HPV 16 genome. Bold lines indicate ORFs. The designed primer MHPVFW and MHPVRE correspond to the L1 region.

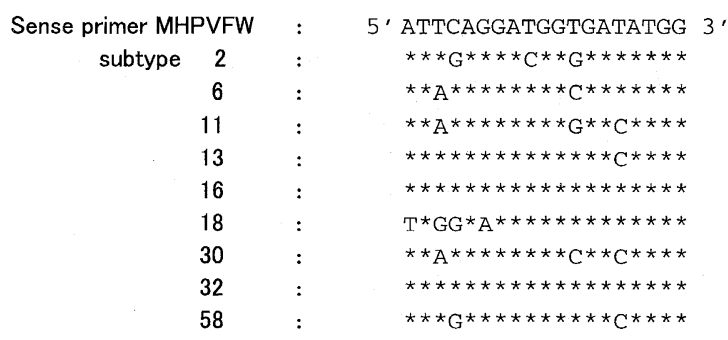

Anti-sense primer MHPVRE : (transfer to sense code Subtype 2

6
11
13
16
18
30
32
58

Fig. 2 Alignment of the consensus primers with the corresponding sequences of HPV subtype 2, 6, 11, 13, 16, 18, 30, 32 and 58. The symbol represents identical bases; mismatched bases are indicated.

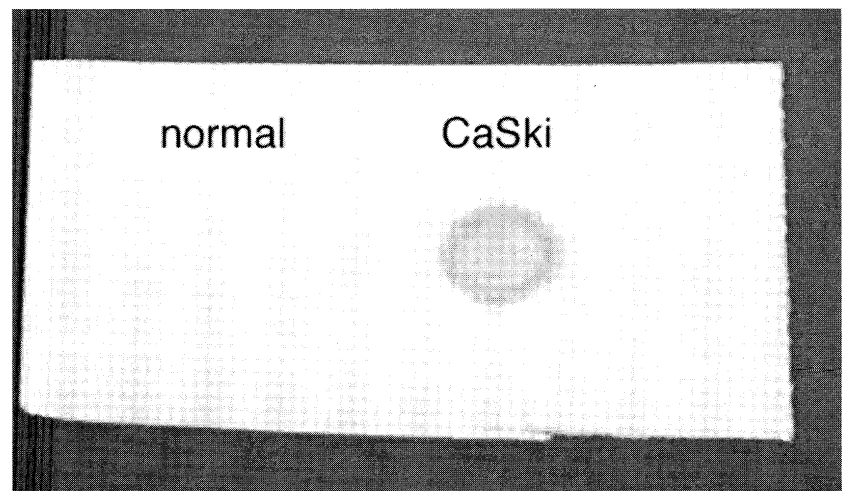

Fig. 3 Dot blot hybridization against extracted DNAs from clinically normal buccal mucous and CaSki cell with digoxigenin labeled PCR amplified fragment. HPV16 control genom was amplified with disigned primers and digoxigenin labeled. The amplified DNA was hybridized with extracted DNA from CaSki cell.

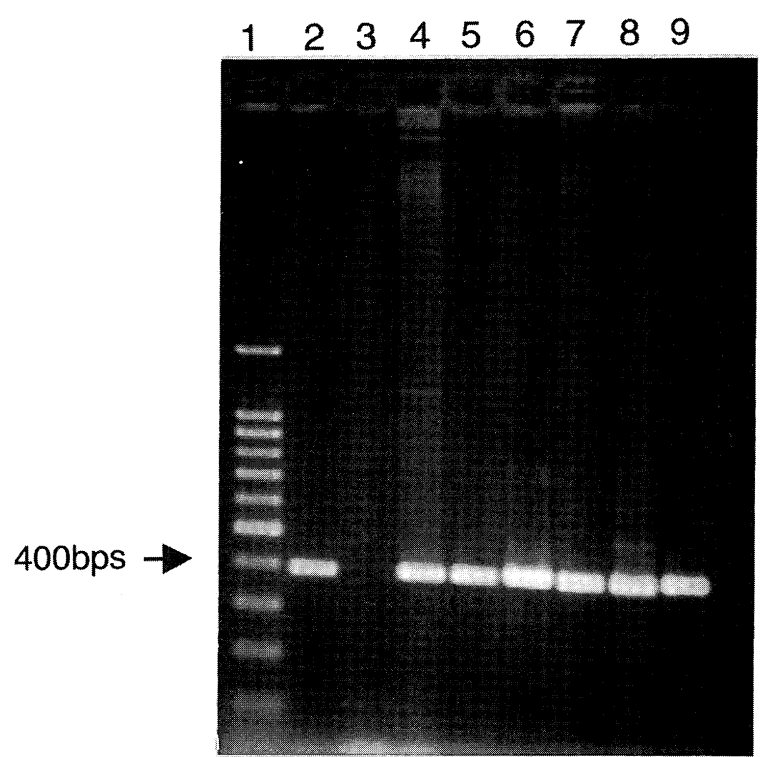

Fig. 4 PCR amplification of control HPV DNA of types 2(lanes 2), 4(lanes 3), 6(lanes 4), 11(lanes 5), 16(lanes 6), 18(lanes 7), 58(lanes 8), and cellular DNA from CaSki (lanes 9) and standard DNA marker(lanes 1).

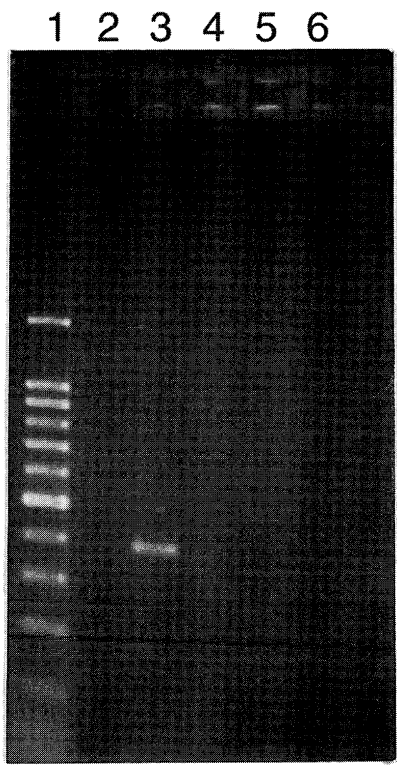

Fig. 5 PCR amplification of clinical samples(oral papilloma) with designed primers(lane 2 to 6 ) and standard maeker(lanes 1). One sample(lanes 3) showed PCR product band. HPV 16, 18 and 33 were not detected from this sample by PCR with control primer. 
were not detected by designed primers, re-amplification with a lower annealing temperature will be necessary for the case which possessed HPV infection by histo-pathologic analysis.

In the examined clinical sample, the PCR product with our designed primer detected subtypes other than subtype 16,18 , and 33. Badaracco et al. (18) found that the most prevalent DNA type in the oral cavity was HPV16 (45.5 $\%$ ) followed by HPV6 (36.4 \%). Kellokoski et al. (19) analyzed the detection ratio of HPV in clinically normal buccal mucousa and clinical lesions by dot blot hybridization followed by PCR amplification and showed that HPV-DNA in the detection ratio of HPV6/11 and HPV16/18 were $22.4 \%$ and $8.2 \%$, respectively. Nielsen et al. (20) showed that HPV was detected in $40.8 \%$ of oral premalignant lesions. However, only a few studies have reported the detection ratio of HPV in Japanese oral papillomas. In this study, one out of the five $(20 \%)$ samples observed HPV-DNA by PCR with the designed consensus primer. The other four specimens were considered to be uninfected or infected with another type of HPV.

The nucleotide sequence is necessary to confirm a subtype of this detected HPV. However, these findings suggest that PCR with this consensus primers can assess the relation between the oral disease and the HPV infection.

\section{References}

1. de Villiers, E.M.(1989) Heterogeneity of the human papillomavirus group. J.Virol. 63, 4898-4903

2. Beaudenon, S., Kremsdorf, D., Croissant, O., Jablonska, S., Wain-Hobson, S. and Orth, G. (1986) A novel type of human papillomavirus associated with genital neoplasias. Nature 321, 246-249

3. Lorincz, A.T., Temple, G.F., Kurman, R.J., Jenson, A.B. and Lancaster, W.D. (1987) Oncogenic association of specific human papillomavirus types with cervical neoplasia. J. Natl. Cancer Inst. 79, 671677

4. Matsukura, T. and Sugase, M. (1990) Molecular cloning of a novel human papillomavirus (type 58) from an invasive cervical carcinoma. Virology 177, 833-836

5. Syrjänen, S.M., Syrjänen, K.J. and Happonen, R.P. (1988) Human papillomavirus (HPV) DNA sequences in oral precancerous lesions and squamous cell carcinoma demonstrated by in situ hybridization. J. Oral Pathol. 273-278.

6. Saiki, R.K., Scharf, S., Faloona, F., Mullis, K.B., Horn, G.T., Erlich, H.A. and Arnheim, N. (1985) Enzymatic amplification of $\beta$-globin genomic sequences and restriction site analysis for diagnosis of sickle cell anemia. Science 230, 1350-1354

7. Pattillo, R.A., Hussa, R.O., Story, M.T., Ruckert,A.C.F., Shalaby, M.R. and Mattingly, R.F. (1977) Tumor antigen and human chorionic gonadotropin in CaSki cells: a new epidermoid cervical cancer cell line. Science 196, 1456-1458

8. Davis, L.G., Dibner, M.D. and Battey, J.F. (1986) Basic Methods in Molecular Biology. Elsevier Science Publishing, New York, 47-50

9. Gregoire, L., Arella, M., Campione-Piccardo, J. and Lancaster, W.D. (1989) Amplification of human papillomavirus DNA sequences by using conserved primers. J. Clin. Microbiol. 27, 2660-2665

10. van den Brule, A.J.C., Snijders, P.J.F., Gordijn, R.L.J., Bleker, O.P., Meijer, C.J.L.M. and Walboomers, J.M. M.(1990) General primermediated polymerase chain reaction permits the detection of sequenced and still unsequenced human papillomavirus genotypes in cervical scrapes and carcinomas. Int. J. Cancer 45, 644-649

11. Manos, M.M., Ting, Y., Wright, D.K., Lewis, A.J., Broker, T.R. and Wolinsky, S.M. (1989) Use of polymerase chain reaction amplification for the detection of genital human papillomaviruses. In Cancer cells. 7 Molecular diagnostics of human cancer, Furth, M. and Greaves, M. eds. Cold Spring Harbor Laboratory Press, New York, 209-214

12. Snijders, P.J.F., van den Brule, A.J.C., Schrijnemakers, H.F.J., Snow, G., Meijer, C.J.L.M. and Walboomers, J.M.M. (1990) The use of general primers in the polymerase chain reaction permits the detection of a broad spectrum of human papillomavirus genotypes. J. Gen. Virol. 71, 173181

13. Shirasawa, H., Tomita, Y., Sekiya, S., Takamizawa, H. and Simizu, B. (1987) Integration and transcription of human papillomavirus type 16 and 18 sequences in cell lines derived from cervical carcinomas. J. Gen.Virol. 68, 583-591

14. Schwarz, E., Freese, U.K., Gissmann, L., Mayer, W., Roggenbuck, B., Stremlau, A. and zur Hauzen, H. (1985) Structure and transcription of human papillomavirus sequences in cervical carcinoma cells. Nature 314, 111-114

15. Pater, M. and Pater, A. (1985) Human papillomavirus type 16 and 18 sequences in carcinoma cell lines of the cervix. Virology 145, 313-318

16. Matsukura, T., Kanda, T., Furuno, A., Yoshikawa, H., Kawana, T. and Yoshiike, K. (1986) Cloning of monomeric human papillomavirus type 16 DNA integrated within cell DNA from a cervical 
carcinoma. J.Virol. 58, 979-982

17. Choo, K.B., Lee, H.H., Pan, C.C., Wu, S.M., Liew, L.N., Cheung, W.F. and Han, S.H. (1988) Sequence duplication and internal deletion in the integrated human papillomavirus type 16 genome cloned from a cervical carcinoma. J.Virol. 62, 1659-1666

18. Badaracco, G., Venuti, A., Di Lonardo, A., Scambia, G., Mozzetti, S., Benedetti Panici, P., Mancuso, S. and Marcante, M.L. (1998) Concurrent HPV infection in oral and genital mucosa. J. Oral Pathol. Med. 27,130-134
19. Kellokoski, J.K., Syrjanen, S.M., Chang, F., Yliskoski, M. and Syrjanen, K.J. (1992) Southern blot hybridization and PCR in detection of oral human papillomavirus (HPV) infections in women with genital HPV infections. J. Oral Pathol. Med. $21,459-464$

20. Nielsen, H., Norrild, B., Vedtofte, P., Praetorius, F., Reibel, J. and Holmstrup, P. (1996) Human papillomavirus in oral premalignant lesions. Eur. J. Cancer B. Oral Oncol. 32, 264-270 